\section{BIBLIOGRAFÍA}

CASTROVIEJO et al. (eds.) -1986/1997- Flora Iberica. Plantas Vasculares de la Península Ibérica e Islas Baleares. Vol. I-VIII. Jardín Botánico, CSIC. Madrid.

MOLERO MESA, J. y F. PÉREZ RAYA. -1987- La flora de Sierra Nevada. Avance sobre el catálogo florístico nevadense. Serv. Publ. Univ. Granada.

MOLERO MESA, J, F. PÉREZ-RAYA y F. VALLE -1992- Parque Natural de Sierra Nevada. Ed. Rueda. Madrid.

MOTA POVEDA, J.F. y F. VALLE TENDERO 1987- Estudio Botánico-Ecológico de las cuencas altas de los ríos Bayárcal, Paterna y Andarax. Servicio de publicaciones de la Diputación de Almería.
RIVAS-MARTÍNEZ, S., A. ASENSI, B. DÍEZ, J. MOLERO \& F. VALLE - 1997- Biogeographical synthesis of Andalusia (S. Spain). Journal of Biogeography 24: 915-928.

SAGREDO, R. -1987- Flora de Almería. Instituto de Estudios Almerienses. Almería.

TUTIN, T. et al. (eds.) -1964/1980- Flora europaea, Vols. 1-5. Cambridge University press. Cambridge.

Aceptado para su publicación en Abril de 1998

Dpto. Biología Vegetal, Facultad de Ciencias, Universidad de Granada. Aptdo. 18001 Granada. Email: fvalle@goliat.ugr.es

\title{
61. THYMUS VULGARIS L., NOVEDAD PARA LA FLORA DE ANDALUCÍA OCCIDENTAL
}

\author{
M. Ángeles MARTÍN MOSQUERO
}

Thymus vulgaris, a new specie in west Andalusia Flora.

Palabras clave. Lamiaceae, Thymus, Andalucía Occidental.

Key words. Lamiaceae, Thymus, west Andalusia.

Thymus vulgaris L. perteneciente a la Sect. Thymus Subsect. Thymus, es una especie que vive preferentemente sobre suelos ricos en bases, sobre todo en calizas y margas, también en terrenos yesosos cuando la influencia de éste no es muy acusada y raramente sobre suelos arenosos. Es frecuente encontrarlo en suelos pedregosos, grietas de rocas o sobre cantiles.

Son matas erectas o decumbentes, que se caracterizan, fundamentalmente, por sus tallos rojizos pubescentes con pelos cortos retrorsos, hojas lineares con margen revoluto, subpecioladas y sin cilios en la base, inflorescencias espiciformes acabezueladas y corolas de hasta $5 \mathrm{~mm}$ más o menos rosadas con anteras púrpuras.

Se distribuye por toda la región Mediterránea occidental europea, desde la Península Ibérica hasta Italia.

En la Península Ibérica está representada por dos subespecies; la subespecie vulgaris L. en la mitad $\mathrm{E}$, haciéndose escasa hacia el $\mathrm{S}$ 
donde se cultiva y asilvestra con facilidad (Morales, 1986), de floración primaveral (Abril-Junio), y la subsp. aestivus (Reuter ex Willk.) A. Bolós \& O. Bolós, endemismo de la región levantina (Castellón, Valencia, Alicante, Ibiza), citado también en Murcia (Esteve 1972, sec. R. Morales 1986) y de floración preferentemente estival (Mayo-Octubre).

Recientemente se ha localizado una población de Thymus vulgaris subsp. vulgaris L. en Cádiz, Chiclana de la Frontera, cerca de la playa, frente a una zona de dunas y bajo un pinar de Pinus pinea L. (22-III-1997, Martín Mosquero SEV 149255) lo cual supone una novedad para la Flora de Andalucía Occidental.

Hay que destacar que el terreno en el que se localiza dicha población parece haber sido removido, lo que ha podido favorecer la presencia de este taxón; aunque en la actualidad parece bien asentada.
AGRADECIMIENTOS. El autor agradece al Dr. Ramón Morales Valverde la revisión del material, así como sus orientaciones y sugerencias.

\section{BIBLIOGRAFÍA}

JALAS, J. -1972- Thymus L. In: T. Tutin et al. (eds.) Flora Europaea 3: 172-182. Cambridge.

MORALES VALVERDE, R. -1986- Taxonomía de los géneros Thymus (excluida la Sec. Serpyllum) y Thymbra en la Península Ibérica. Ruizia 3.

MORALES VALVERDE, R. 1987- Thymus L. In: B. Valdés et al. (eds.), Flora de Andalucia occidental 2: 441-446. Barcelona.

Aceptado para su publicación en Octubre de 1997

Dirección del autor. Departamento de Biología Vegetal y Ecología. Apdo. 1095. 41080, Sevilla.

\title{
62. APORTACIONES A LA FLORA DE CÓRDOBA
}

\author{
Rafael PINILLA, Rafael TAMAJÓN y Jesús M. MUÑOZ
}

New records for the flora of Cordoba

Palabras clave. Corología, Córdoba, Andalucía, España.

Key words. Chorology, Cordoba, Andalusia, Spain.

Se aportan nuevas localidades de la provincia de Córdoba, de interés corológico, para un total de 53 especies. En su mayoría proceden del Parque Natural "Sierra de Hornachuelos". Este espacio natural protegido tiene una extensión de unas 65.000 hectáreas,

Estudio financiado por la Consejería de Medio Ambiente de la Junta de Andalucía, Proyecto de Investigación: «Cartografía y Evaluación de la vegetación del Parque Natural Sierra de Hornachuelos». 